\title{
Análise do perfil vertical do Vento no Centro de Lançamento de Alcântara com uso de Análise de Componentes Principais
}

\author{
Analysis of the vertical wind profile at the Alcântara Launch Center using Principal Components \\ Analysis
}

\author{
Paola do Nascimento Silva' \\ Cleber Souza Corrêa"
}

\section{Resumo}

O objetivo deste estudo é fazer uma análise do comportamento do perfil vertical do vento, utilizando dados de radiossondagem no Centro de Lançamento de Alcântara (CLA), por meio do uso da técnica estatística multivariada da Análise das Componentes Principais (ACP), verificar se há presença de fluxos no perfil vertical do vento. Estes fluxos podem caracterizar circulações locais e estar associados com circulações do tipo brisa marítima, e também pode estar associado a circulações ao nível de mesoescala sinótica, tais como os Jatos de Baixos Níveis (JBN). Os resultados mostraram que nas três primeiras componentes no período noturno há presença de JBN, com $85 \%$ da variância explicada. A ocorrência dos JBN apresentou alturas típicas nas componentes, sendo a primeira com altura de 800 metros (direção média 60 a 70 graus), a segunda com altura de 400 metros (direção média 40 a 50 graus) e a terceira com 200 metros (direção média 50 a 60 graus). Tais JBN encontrados podem estar associados a processos relacionados a Camada Limite Planetária (CLP) no período noturno, como por exemplo o vento máximo de inversão e brisas.

Palavras-chave: Brisa Marítima; Jatos de Baixos Níveis; Análise de Componentes Principais

\section{Abstract}

The objective of this study is to perform a vertical wind profile analysis using radiosonde data at the Alcântara Launch Center (ALC), using the multivariate statistical technique of the Principal Components Analysis (PCA), to verify if there is a presence of flows in the vertical wind profile. These flows may characterize local circulations and be associated with sea breeze-type circulations, and may also be associated with synoptic mesoscale level circulations, such as Low-Level Jets (LLJ). The results showed that in the first three components in the nocturnal period there is a presence of LLJ, with $85 \%$ of the variance explained. The occurrence of LLJ presented typical heights in the components, the first one with a height of 800 meters (average direction 60 to 70 degrees), the second with a height of 400 meters (mean direction 40 to 50 degrees) and the third with 200 meters average 50 to 60 degrees). These LLJs may be associated with processes related to the Planetary Boundary Layer (PBL) at night, such as maximum wind inversion and breezes.

Keywords: Maritime Breeze; Low Level Jets; Principal Component Analysis 


\section{Introdução}

A região de interesse para o estudo é o Centro de Lançamento de Alcântara (CLA), localizado no município de Alcântara e, está a $2^{\circ} 24^{\prime} \mathrm{S}$ de latitude e $44^{\circ} 25^{\prime}$ O de longitude, no estado do Maranhão, onde o clima predominante é o tropical úmido. O município de Alcântara possui características típicas, com uma região de superfície lisa (oceano) próximo a uma superfície rugosa (continente). O relevo local lembra um degrau, pois o continente encontra uma relativa variação topográfica (falésia) com grande inclinação e altura de aproximadamente $50 \mathrm{~m}$, sendo o topo uma região relativamente plana. Próximo a esta falésia, a uma distância da borda de $150 \mathrm{~m}$, encontra-se a rampa de lançamento de foguetes do CLA (ROBALLO E FISCH, 2008). O CLA situa-se próximo ao Equador e recebe forte influência da Zona de Convergência Intertropical (ZCIT); das Linhas de Instabilidade da Costa Amazônica; dos ventos alísios; de contrastes térmicos locais entre o mar adjacente e o continente, caracterizado por forte presença da brisa marítima; entre outros fenômenos, que normalmente ou esporadicamente estão presentes sobre esta área (PEREIRA et al., 2002).

É necessário que se entenda o comportamento climatológico da região para que se possa realizar os lançamentos de foguetes no CLA, evitando-se desta forma acidentes e prejuízos. Portanto é muito importante conhecer as diferentes escalas físicas que podem ser observadas no perfil vertical do vento próximo a superfície pois, neste perfil podem ser registrados diferentes estruturas que caracterizam uma dinâmica complexa, influenciando o comportamento resultante do vento próximo da superfície. Neste aspecto podem ser citados circulações do tipo brisa marítima e fluxos no perfil vertical, e os perfis podem ter características de fluxos com vento máximo ou até podem ocorrer algumas oscilações inerciais no campo do vento que, adicionadas ao mecanismo de desacoplamento da Camada Limite Planetária, estável e noturna, geram Jatos de Baixos Níveis (JBN). Os JBN são sistemas de vento com altas velocidades abaixo de um ou dois quilômetros, com uma extensão horizontal de aproximadamente de $500 \mathrm{~km}$, dimensão comum de escala sub-sinótica e mesoescala (MARENGO E SOARES, 2002). Segundo Ferreira e Calbete (2002), os JBN correspondem a um processo eficiente de transporte de calor e umidade das regiões tropicais para os extratrópicos, tendo como consequência formação ou intensificação de tempestades severas. Eventos de JBN podem acontecer durante todo ano, porém são detectadas com maior frequência entre os meses de dezembro a fevereiro (MARENGO E SOARES, 2002). Os JBN podem caracterizar um ciclo de existência diário e noturno, mostrando um comportamento que se inicia no final da tarde do dia anterior e pode estender-se até a próxima manhã no dia seguinte, caracterizando e modulando um transporte de vapor de água e de energia no período noturno e nas primeiras horas do dia (BONNER et al., 1968; STENSRUD, 1996; WHITEMAN et al., 1997; LIU E LIANG, 2010; PU E DICKINSON, 2014; DOUBLER et al., 2015).
Alguns estudos observacionais já foram realizados no CLA, como Roballo e Fisch (2008) que analisaram parâmetros físicos associados ao vento na região de Alcântara. Os seus resultados mostraram que a velocidade de fricção $\left(u^{*}\right)$ foi igual a $0,32 \pm 0,13 \mathrm{~m} / \mathrm{s}(0,46 \pm 0,11)$ para os meses de chuva (seco), enquanto que o parâmetro de rugosidade (z0) foi igual a $0,19 \pm 0,32(0,06 \pm 0,05 \mathrm{~m})$ para os meses de chuva (seco), mostrando a sazonalidade destes parâmetros. O expoente $\alpha$ da velocidade potencial variou de 0,19 (julho) a 0,27 (março), decrescendo este valor com a altura tanto no período de chuvas, quanto no período seco. A validação dos valores de a, com dados de vento dos anos de 2004 e 2005, mostraram que, para o mês representativo da estação chuvosa (março), os valores estimados foram superiores aos observados na Torre Anemométrica, devido à fraca condição de neutralidade. Para o mês seco, as velocidades calculadas e observadas foram muito próximas, uma vez que a velocidade do vento é forte (valor médio superior a $10 \mathrm{~m} / \mathrm{s}$ ), produzindo muita mistura turbulenta na forma mecânica e implicando em uma atmosfera neutra.

Um outro estudo com análise do perfil de vento em Alcântara foi realizado por Gisler et al. (2011), onde foi realizado estudos estatísticos com dados de torre anemométrica e dados de radiossonda, baseado em dados de vento (direção e velocidade do vento) coletados entre 1995 e 1999, os quais foram realizados em seis níveis diferentes: 6.0, 10.0, 16.3, 28,5, 43,0 e 70,0 m. Esta análise foi feita para os meses chuvosos típicos (março) e secos (setembro). Na análise o total de dados durante a estação chuvosa (março) foi de 76.882 perfis de vento (intervalo de tempo de dez minutos) e durante a estação seca (setembro) foi de 109.809 perfis. Calculou-se a velocidade média (ou intensidade) do vento, desvio padrão, mediana, moda e direção do vento predominante. A direção predominante foi de Nordeste com 33 e $40 \%$ para as estações chuvosa e seca, respectivamente. Os valores médios da velocidade do vento mostraram uma dependência com a altura e foi observado que os maiores níveis da torre anemométrica possuem a maior velocidade do vento no período seco $\left(8,2 \mathrm{~ms}^{-1}\right)$. Os valores das velocidades médias do vento observadas foram $6,4 \mathrm{~ms}^{-1}$ para a estação seca e $4,1 \mathrm{~ms}^{-1}$ durante a estação chuvosa.

No trabalho de Souza e Oyama (2017) sobre o potencial de Brisa ao Longo da Costa Norte e Nordeste, utilizando dados de reanalise, pode-se observar que o máximo diário do vento zonal (mínimo), que representa o potencial de brisa terrestre (mar), ocorreu às 0700 UTC $(\sim 1900$ UTC). Ao longo da costa orientada para o zoneamento, o potencial da brisa estava principalmente relacionado ao vento meridional e se estendia para o interior e para o mar ao longo de 2 a 3 graus da costa. Na costa, o máximo diário do ciclo meridional do vento (mínimo), que representa o potencial de brisa terrestre (mar), ocorreu em 1000 UTC ( 2200 UTC). Este resultado é importante pois mostra a modulação do perfil vertical do vento para a região do CLA. Porém ainda não há estudo a respeito da caracterização da existência de JBN no perfil vertical do vento e sua associação com a brisa marítima especificamente para a região do CLA. 
Desta forma, o objetivo deste estudo é analisar o perfil vertical do vento no CLA e determinar se existe JBN através de ACP e, para a realização foi analisado radiossondagens entre o período diurno e noturno. A sua observação e caracterização permitirá uma maior compreensão dos mecanismos e do comportamento do perfil vertical do vento, aumentando o conhecimento físico e dinâmico do vento nas atividades aeroespaciais desenvolvidas no CLA.

\section{Materiais e Métodos}

Foi realizado a observação do perfil vertical do vento com radiossondagens em alta resolução no período de 01 de julho a 30 de novembro de 2014, este período foi utilizado por ter uma observação contínua, com 153 dias. Foram gerados arquivos diurno e noturno, que eram compostos por uma matriz com 3 colunas, sendo elas de altura, direção e intensidade do vento. Os arquivos, do tipo (.prn), foram utilizados para se realizar uma análise composta da estatística multivariada de $\mathrm{ACP}$, através do software GENSTAT. A ACP supõe que uma variável randômica $\mathrm{X}_{1}, \ldots, \mathrm{X}_{\mathrm{P}}$ de interesse tem uma determinada distribuição multivariada, com um vetor médio $\mu$ e matriz variância-covariância $\mathbf{S}$. $\mathrm{O} \lambda_{\mathrm{q}}$ é o maior número de raízes características de $\mathbf{S}$, que são todas independentes. A matriz variância-covariância $\mathbf{S}$ e o vetor $\mathbf{X}$ são de mesma ordem. Os coeficientes da matriz a são elementos de um autovetor da matriz variância-covariância $\mathbf{S}$, correspondendo ao maior número de raízes de $\lambda \mathrm{ij}$, e seus autovalores, são menores em número que as $\mathrm{p}$ variáveis (CORRÊA et al., 2007). A partir da analise dos autovetores da matriz a, cada coluna representa uma componente da variância total e cada linha desta matriz pode representar a contribuição de determinada componente para a ocorrência de um determinado evento. Os autovetores da matriz a geometricamente podem ser compreendidos como as projeções das amostras na direção da componente principal, e tal fato implica que na analise destes coeficientes da matriz a (autovetores), o maior valor do coeficiente representa a sua maior contribuição.

A principal característica das n-componentes principais geradas pelas n-variáveis, além da ortogonalidade, é que são obtidos em ordem decrescente de máxima variância, ou seja, a componente principal 1 detém mais informação estatística que a componente principal 2, que por sua vez tem mais informação estatística que a componente principal 3 e assim por diante (NETO E MOITA, 1998). Realizou-se a análise com 4 componentes principais e, foi utilizado a matriz de autovalores na caracterização da ocorrência de cada componente na série temporal. Desta forma, foi possível selecionar a componente que obteve o maior valor em modulo para cada observação no período diurno e noturno.

Para cada uma das 4 componentes da ACP foi gerado dois gráficos, um diurno e um noturno com a média de todas as observações selecionadas por componente e, através desses gráficos foi possível fazer análises a respeito da velocidade e direção do vento em suas dife- rentes alturas.

\section{Resultados}

A tabela 1 apresenta a porcentagem das componentes principais e a variância explicada pela ACP para a direção e velocidade diurno e noturno, no período de 01 de julho a 30 de novembro de 2014 .

Tabela 1 - Análise de componentes principais da direção e velocidade do vento no CLA.

\begin{tabular}{llllll}
\hline & \multicolumn{3}{c}{ Componentes } & & $\begin{array}{c}\text { Variância } \\
\text { Explicada }\end{array}$ \\
& $1^{\circ}$ & $2^{\circ}$ & $3^{\circ}$ & $4^{\circ}$ & \\
\hline $\begin{array}{l}\text { Direção } \\
\text { Diurno }\end{array}$ & 41.86 & 37.01 & 9.22 & 5.58 & 93,67 \\
$\begin{array}{l}\text { Direção } \\
\text { Noturno }\end{array}$ & 82.66 & 10.02 & 3.35 & 1.29 & 97,32 \\
$\begin{array}{l}\text { Velocidade } \\
\text { Diurno }\end{array}$ & 81.93 & 9.17 & 3.62 & 2.35 & 97,07 \\
$\begin{array}{l}\text { Velocidade } \\
\text { Noturno }\end{array}$ & 41.41 & 31.51 & 14.16 & 4.97 & 92,05 \\
\hline
\end{tabular}

A tabela 2 será utilizada para a classificação da intensidade dos JBN encontrados nas componentes da ACP. Segundo Corrêa et al. (2001), dois critérios são usados nessa classificação e ambos devem ser satisfeitos simultaneamente: um especifica o valor máximo da velocidade do vento e o outro especifica a diminuição do valor da velocidade do vento acima do seu núcleo máximo até atingir a velocidade de valor mínimo.

Tabela 2: Categorias de classificação dos JBN

\begin{tabular}{ccc}
\hline JBN & \multicolumn{2}{c}{ Definição } \\
Categoria & Vento máx. $(\mathrm{m} / \mathrm{s})$ & Cizalhamento $(\mathrm{m} / \mathrm{s})$ \\
\hline JBN Fraco & $>6$ & $\geq 5$ \\
JBN-0 & $\geq 10$ & $\geq 5$ \\
JBN-1 & $\geq 12$ & $\geq 6$ \\
JBN-2 & $\geq 16$ & $\geq 8$ \\
JBN-3 & $\geq 20$ & $\geq 10$ \\
\hline
\end{tabular}

Adaptado de: Corrêa et al. (2001)

As figuras 1 e 2 apresentam o perfil vertical do vento médio da componente principal 1 para o período diurno e noturno, respectivamente. Em ambos os perfis pode se observar a presença de fluxos no perfil do vento, porém na Figura 2 observa-se a existência de JBN-0, com magnitude maior que $10 \mathrm{~ms}^{-1} \mathrm{e}$ cisalhamento da ordem de 5 $\mathrm{ms}^{-1} \mathrm{e}$, está localizado na altura de $800 \mathrm{~m}$ e corresponde com uma percentagem de ocorrência total da variância da ordem de $40 \%$ e uma direção média da ordem de 60 a 70 graus.. Na figura 1 observa-se o vento máximo na 
altura de $1000 \mathrm{~m}$ e mostra na altura deste fluxo médio a magnitude da ordem de $13 \mathrm{~ms}^{-1}$, possuindo uma direção média de 90 graus. Existe uma diferença na direção entre o dia e a noite, no caso da noite apresenta um desvio para o norte, sendo possivelmente uma influência da circulação de brisa oceano/continente.

A figura 3 corresponde ao perfil vertical do vento médio diurno da componente 2 e é caracterizado pela ausência de JBN. Durante o dia a velocidade do vento foi menor na superfície e, a partir de $200 \mathrm{~m}$ de altitude oscilava entre $10 \mathrm{~ms}^{-1}$ e $12 \mathrm{~ms}^{-1}$ caracterizando um fluxo com vento máximo e altura de sua direção média da ordem de 70 graus. Na figura 4, sendo ela a de período noturno, o perfil vertical do vento apresentou a existência de um JBN Fraco a $400 \mathrm{~m}$ com magnitude aproximadamente de $9 \mathrm{~ms}^{-1}$, cisalhamento da ordem de $5 \mathrm{~ms}^{-1}$, direção média da ordem de 40 a 50 graus na altura correspondente ao JBN e uma variância total da ordem de $30 \%$. A primeira e segunda componente do perfil vertical do vento médio noturno são responsáveis por $70 \%$ da variância total explicada e, se caracterizam pela existência de JBN do tipo JNB-0 e JBN-1.

Os perfis verticais do vento diurno e noturno da terceira componente estão representadas nas figuras 5 e 6. Na figura 5 é possível observar um fluxo de vento máximo na altura de $900 \mathrm{~m}$. já na figura 6 do perfil do vento observa-se a existência de um JBN do tipo JBN-0 na altura de $200 \mathrm{~m}$, tendo uma direção média da ordem de 50 a 60 graus e uma porcentagem de variância total da ordem de $14 \%$ do período analisado.

As figuras 7 e 8 apresentam a componente principal 4. Há ocorrência de vento máximo no período do dia e da noite. Durante o dia o fluxo se encontra a $700 \mathrm{~m} \mathrm{e}$, durante a noite há presença de JBN em $800 \mathrm{~m}$, sendo classificado como JBN-0. Está componente explica a variância total na ordem de 4 a $5 \%$.

Analisando todas as 4 componentes principais da ACP, foi possível observar que durante o período diurno houve ocorrência de fluxos que caracterizam vento máximo, mas não JBN, já no período noturno, no perfil vertical do vento médio das primeiras três componentes havia a presença de JBN do tipo JNB-0 e JBN-Fraco, com

Figura 1 - Direção e velocidade do vento médio diurno da $1^{\circ}$ componente da ACP, no CLA para o período de julho a novembro de 2014.
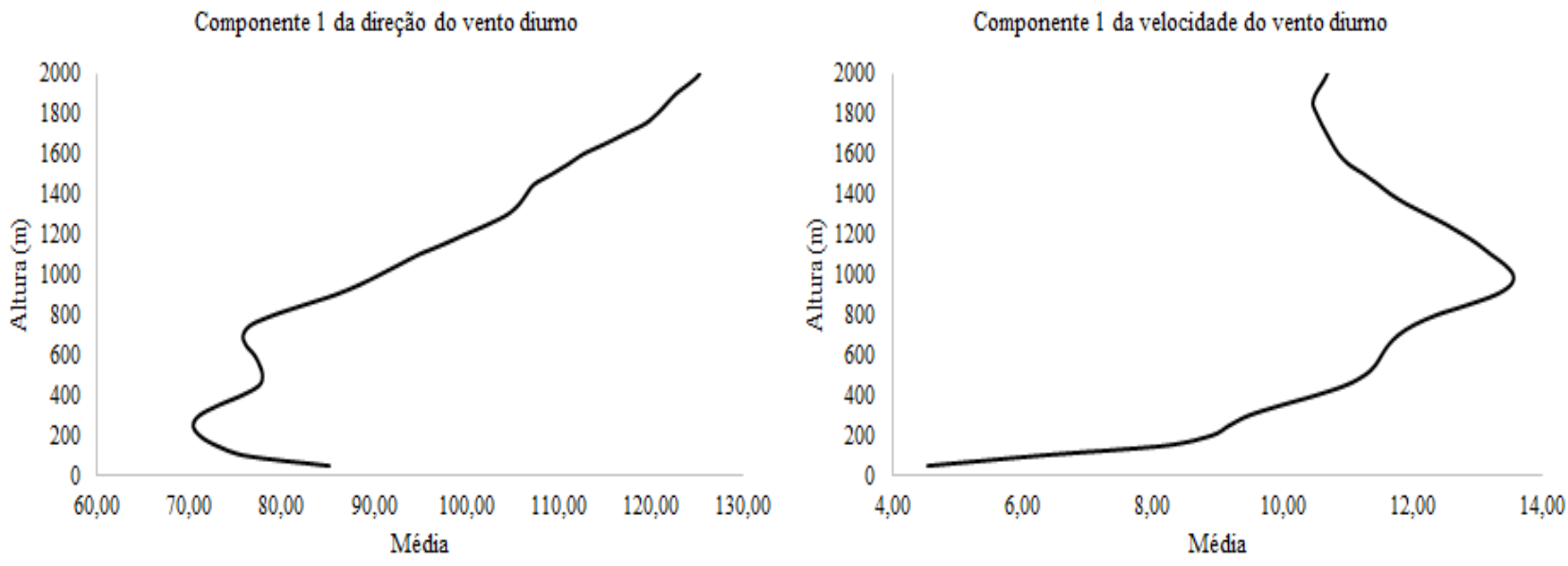

Figura 2 - Direção e velocidade do vento médio noturno da $1^{\circ}$ componente da ACP, no CLA para o período de julho a novembro de 2014.
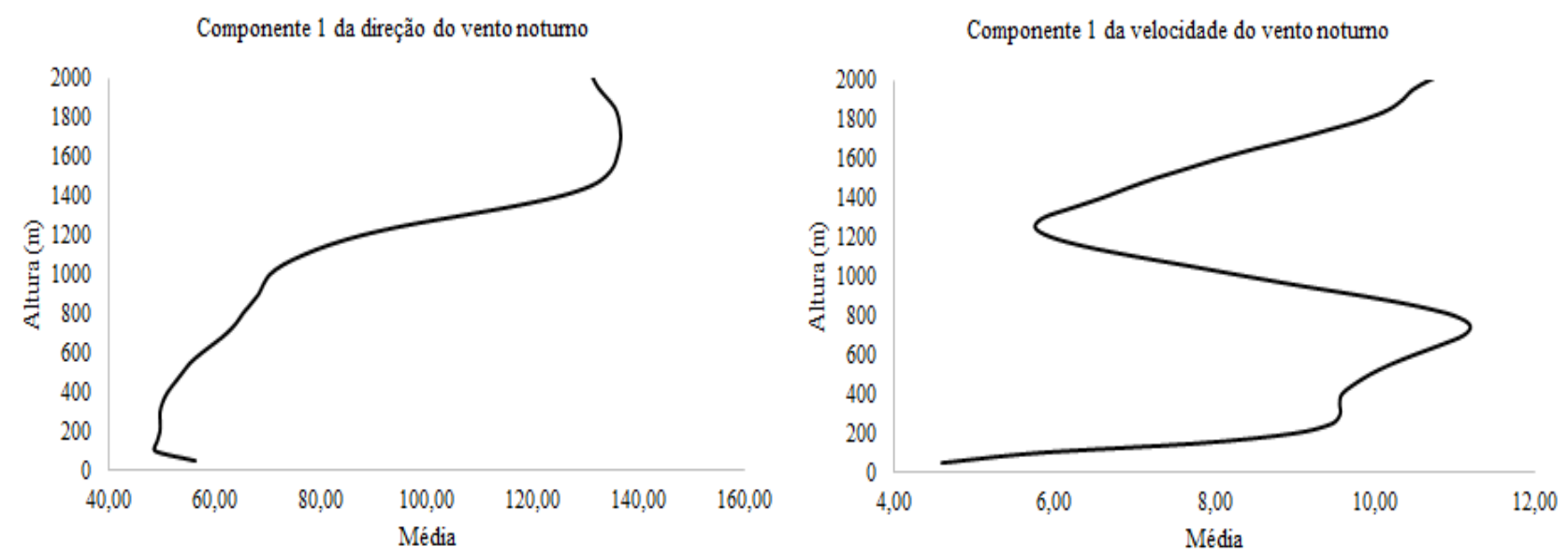
Figura 3 - Direção e velocidade do vento médio diurno da $2^{\circ}$ componente da ACP, no CLA para o período de julho a novembro de 2014.
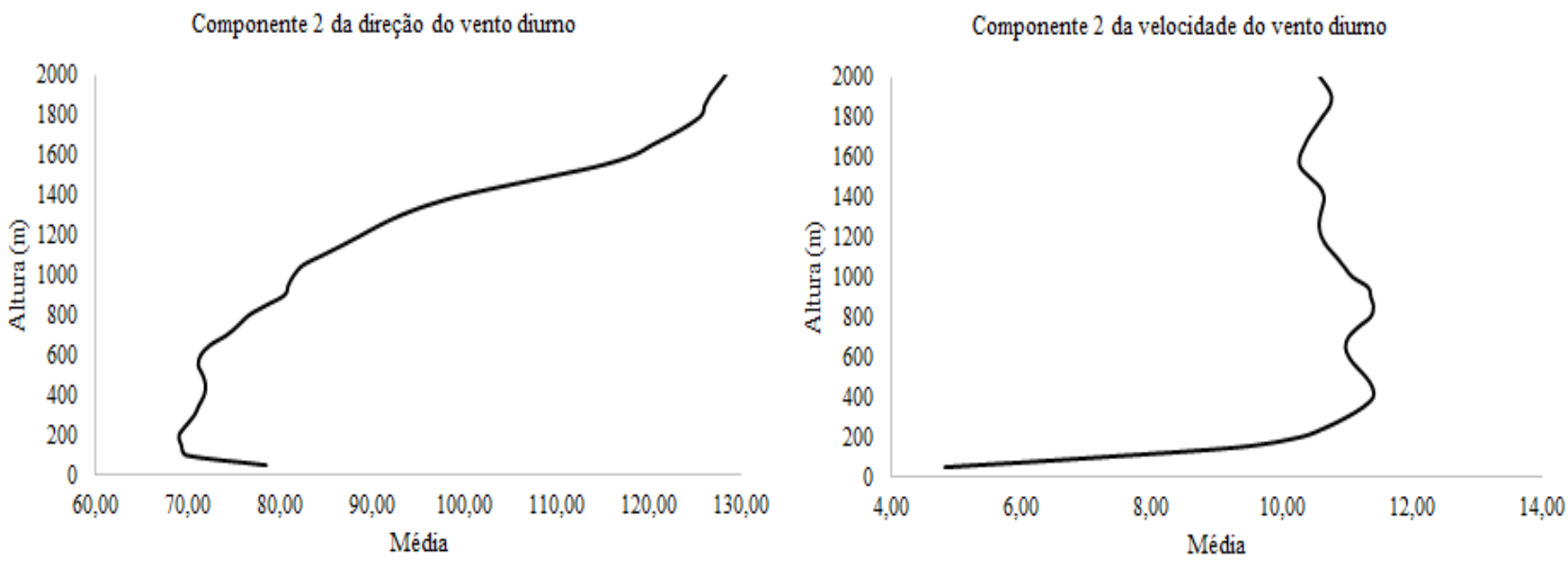

Figura 4 - Direção e velocidade do vento médio noturno da $2^{\circ}$ componente da ACP, no CLA para o período de julho a novembro de 2014.
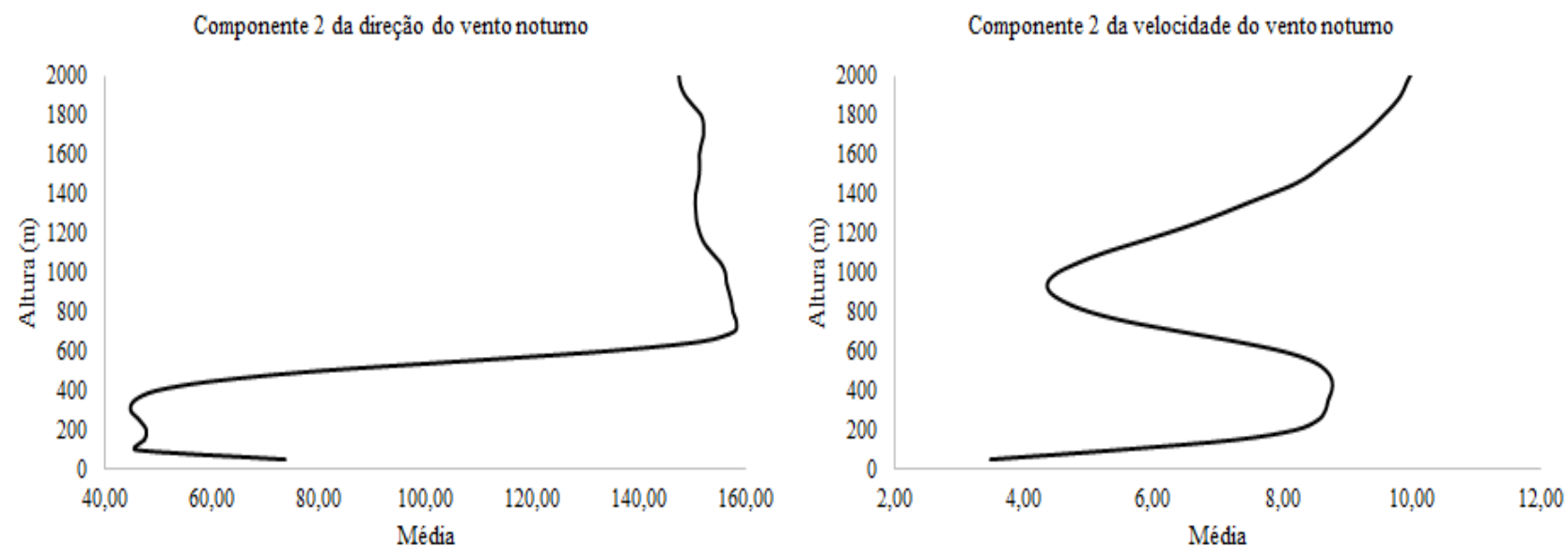

Figura 5 - Direção e velocidade do vento médio diurno da $3^{\circ}$ componente da ACP, no CLA para o período de julho a novembro de 2014.
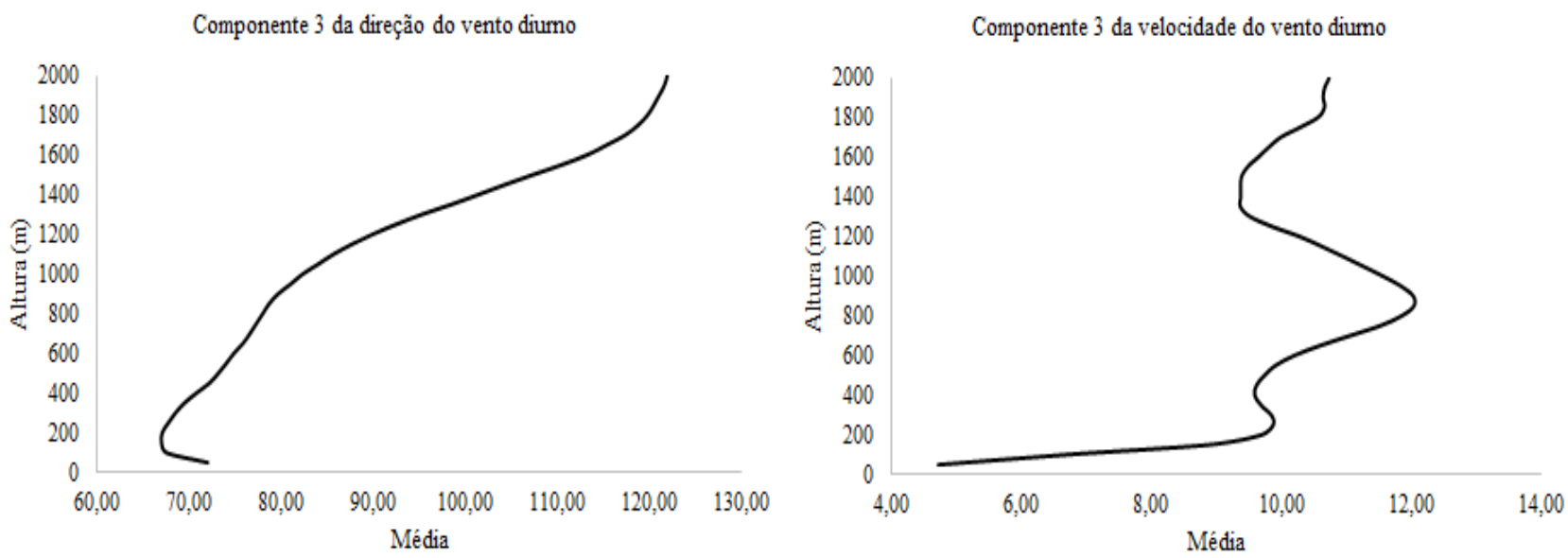
Figura 6 - Direção e velocidade do vento médio noturno da $3^{\circ}$ componente da ACP, no CLA para o período de julho a novembro de 2014.
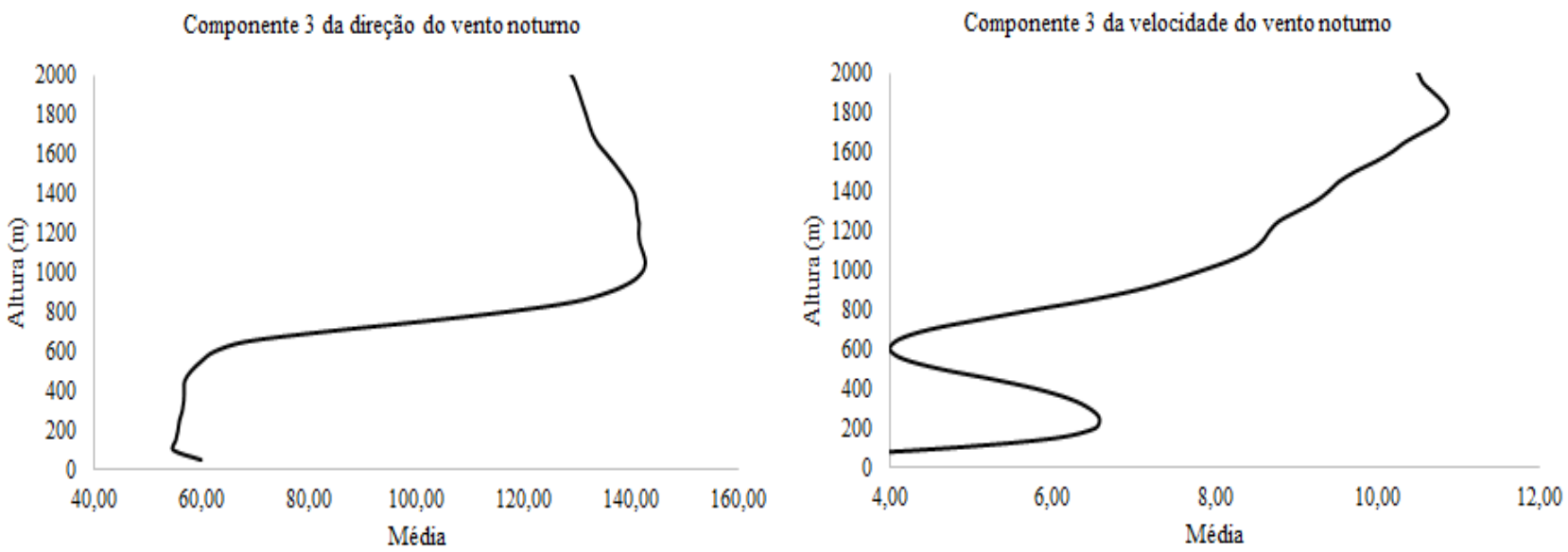

Figura 7 - Direção e velocidade do vento médio diurno da $4^{\circ}$ componente da ACP, no CLA para o período de julho a novembro de 2014.
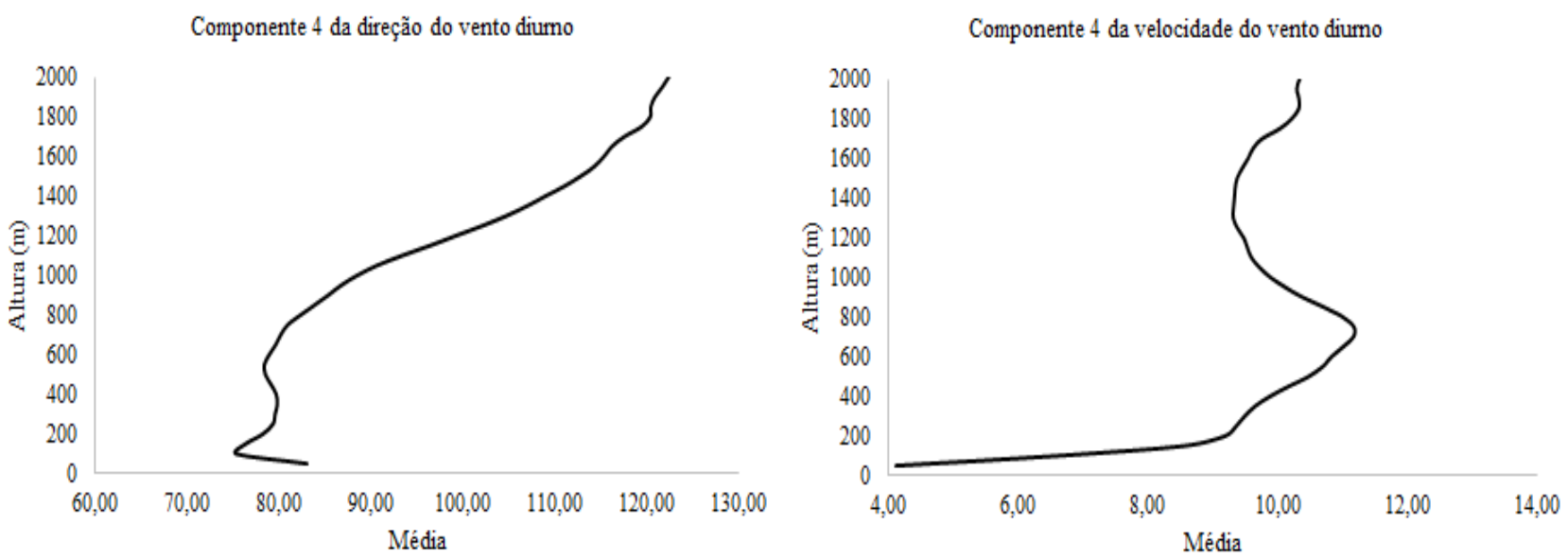

Figura 8 - Direção e velocidade do vento médio noturno da $4^{\circ}$ componente da ACP, no CLA para o período de julho a novembro de 2014.
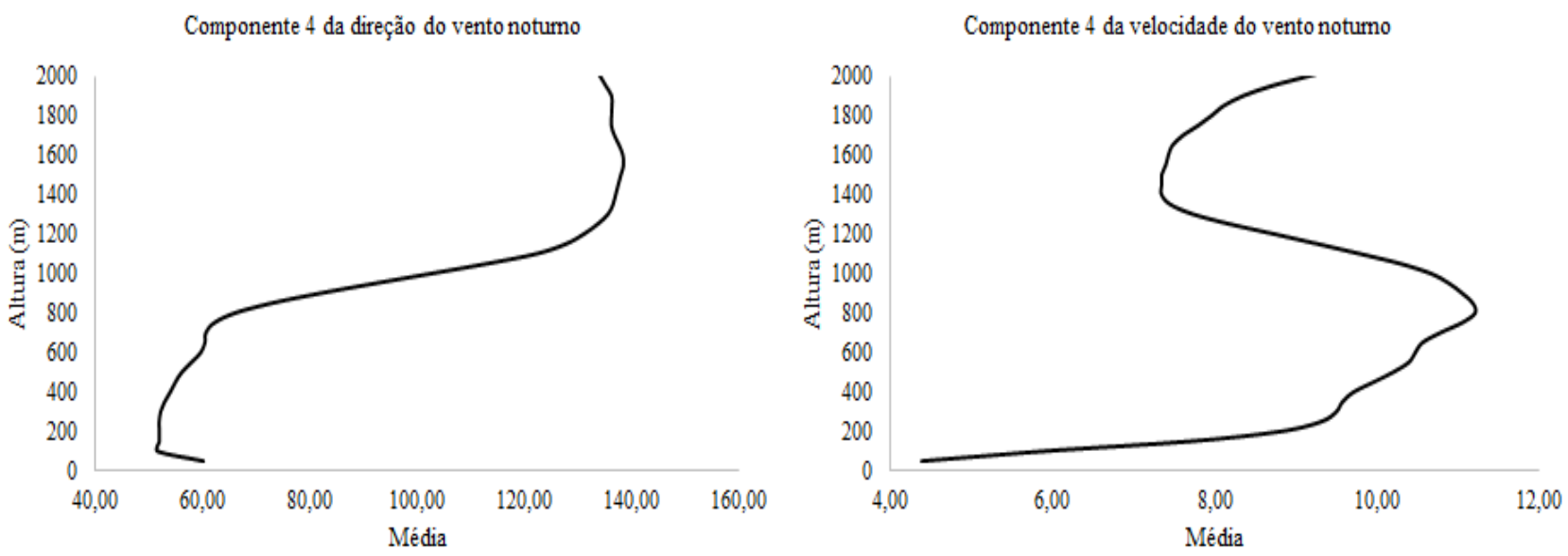
variância total explicada na ordem de $85 \%$. Este resultado é importante, pois na literatura não foi ainda observado a existência de JBN na região de estudo. Este trabalho permite ainda uma discussão sobre a ocorrência de brisa na região do CLA.

\section{Conclusões}

Através da utilização da técnica de modelagem estatística multivariada da ACP, foi possível ter uma boa visualização do perfil vertical do vento no CLA. O que também permitiu a identificação da ocorrência de JBN, sendo eles do tipo JNB-Fraco e JNB-0 no período noturno e com variância explicada de $85 \%$. As três primeiras componentes principais do perfil vertical do vento médio mostraram três alturas típicas, sendo a primeira componente com altura de 800 metros (direção média 60 a 70 graus), a segunda componente com altura de 400 metros (direção média 40 a 50 graus) e a terceira componente com 200 metros (direção média 50 a 60 graus). Tal característica pode estar associada a uma complexa resposta dinâmica de diferentes escalas meteorológicas associadas a estrutura do perfil vertical do vento. No caso da altura mais alta ( 800 metros) e a altura mais baixa (200 metros) é provável que haja processos associados a Camada Limite Planetária no período noturno, como por exemplo o vento máximo de inversão e brisa. Em trabalhos futuros seria interessante analisar séries temporais maiores, com uma análise e descrição de sua variabilidade sazonal e tentar associar com processos físicos da circulação de brisa marítima na região e, também utilizar as radiossondagens de São Luiz como observação mais próxima da região de Alcântara, buscando aprofundar um maior conhecimento da estrutura vertical da dinâmica do perfil do vento na região de interesse para as atividades aeroespaciais.

\section{Agradecimentos}

Este trabalho é parte de um projeto de iniciação científica da primeira autora sob orientação do segundo autor. A primeira autora agradece ao CNPq o privilégio concedido da bolsa de iniciação científica e, ao segundo autor pela orientação, suporte, incentivo e confiança.

\section{Referências}

BONNER, W. D.; ESBENSEN, S.; GREENBERG, R. Kinematics of the low-level jet. Journal of Applied Meteorology, v. 7, n. 3, p. 339-347, 1968.

CORRÊA, C. S.; CLARKE, R. T.; SILVEIRA, A. L. L. Estudo da ocorrência de Fluxos no perfil vertical do vento na baixa Atmosfera com Análise das Componentes Principais (ACP) e a sua relação com a precipitação no Rio Grande do Sul. Revista Brasileira de Meteorologia, v.22, n.1, 121-127, 2007.
CORRÊA, C. S.; DALLAROSA, R. L. G.; DEGRAZIA, G. A. Estudo Observacional dos Jatos de Nível Baixo Sobre a Região Metropolitana de Porto Alegre. Revista Brasileira de Recursos Hídricos, Volume 6 n.4, 19-27, 2001.

DOUBLER, D. L. et al. An NARR-Derived Climatology of Southerly and Northerly Low-Level Jets over North America and Coastal Environs. Journal of Applied Meteorology and Climatology, v. 54, n. 7, p. 1596-1619, 2015.

FERREIRA, S. H. S.; CALBETE, N. O. Estudo de caso de jatos de baixos níveis na América do sul ocorridos em 1999. In: 12 CONGRESSO BRASILEIRO DE METEOROLOGIA. Foz do Iguaçú: SBMET, 2002.

GISLER, C. A. F.; FISCH, G.; CORRÊA, C. S. Statistical analysis of wind profile in the surface layer at the Alcântara launching center. Journal of Aerospace Technology and Management, v. 3, n. 2, p. 193-202, 2011.

LIU, S.; LIANG, X. Observed diurnal cycle climatology of planetary boundary layer height. Journal of Climate, v. 23, n. 21, p. 5790-5809, 2010.

MARENGO, J. A.; SOARES, W. R. Episódios de Jatos de Baixos Níveis ao Leste dos Andes durante 13-19 de abril de 1999. Revista Brasileira de Meteorologia, v. 17, n. 1, p. 35-52, 2002.

NETO, J. M. M.; MOITA, G. C. Uma introdução à análise exploratória de dados multivariados. Química nova, v. 21, n. 4, p. 467-469, 1998.

PEREIRA, E. I. et al. Atlas Climatológico do Centro de Lançamento de Alcântara-MA. São José dos Campos: CTA/IAE-Divisão de Ciências Atmosféricas, 2002.

PU, B.; DICKINSON, R. E. Diurnal spatial variability of Great Plains summer precipitation related to the dynamics of the low-level jet. Journal of the Atmospheric Sciences, v. 71, n. 5, p. 1807-1817, 2014.

ROBALLO, S. T.; FISCH, G. Escoamento atmosférico no Centro de Lançamento de Alcântara (CLA): parte I-aspectos observacionais. Revista Brasileira de Meteorologia, v. 23, n. 4, p. 510-519, 2008.

SOUZA, D. C.; OYAMA, M. D. Breeze Potential Along the Brazilian Northern and Northeastern Coast. Journal of Aerospace Technology and Management, v. 9, n. 3, p. 368-378, 2017.

STENSRUD, D. J. Importance of low-level jets to climate: A review. Journal of Climate, v. 9, n. 8, p. 1698-1711, 1996.

WHITEMAN, C. D.; BIAN, X.; ZHONG, S. Low-level jet climatology from enhanced rawinsonde observations at a site in the southern Great Plains. Journal of Applied Meteorology, v. 36, n. 10, p. 1363-1376, 1997. 


\section{Contribuição dos autores}

Paola do Nascimento Silva

Contribuições substanciais para a concepção do trabalho;

análise e interpretação de dados e redigiu o trabalho.

Cleber Souza Corrêa

Contribuições substanciais para a concepção do trabalho;

análise e interpretação de dados e realizou uma revisão substancial no trabalho. 